\title{
Erratum to: Image Fusion by Hierarchical Joint Sparse Representation
}

\author{
Yao Yao $^{1} \cdot$ Ping Guo $^{1} \cdot \mathrm{Xin}_{\mathrm{Xin}^{1}} \cdot \mathrm{Ziheng}_{\mathrm{Jiang}}{ }^{1}$
}

Published online: 20 May 2015

(C) Springer Science+Business Media New York 2015

\section{Erratum to: Cogn Comput (2014) 6:281-292 \\ DOI 10.1007/s12559-013-9235-y}

Unfortunately, the corresponding author information was incorrect in the original publication of this article. The correct information is given below.

Dr. Xin Xin is the main corresponding author and Dr. P. Guo is the co-corresponding author.

The online version of the original article can be found under doi:10.1007/s12559-013-9235-y.

\footnotetext{
Ping Guo

pguo@ieee.org

xxin@bit.edu.cn

Yao Yao

bityaoyao@bit.edu.cn

Ziheng Jiang

jiangziheng@bit.edu.cn

1 School of Computer Science and Technology, Beijing Institute of Technology, Beijing 100081, China
}

$\triangle$ Xin Xin 